\title{
Risk of cancer in persons with AIDS in Italy, 1985-1998
}

\section{Dal Maso*, , S Franceschi ${ }^{2}$, J Polesel', C Braga ${ }^{2}$, P Piselli $^{3}$, E Crocetti ${ }^{4}$, F Falcini ${ }^{5}$, S Guzzinati ${ }^{6}$, R Zanetti $^{7}$, $M$ Vercelli ${ }^{8}$ and G Rezza ${ }^{9}$ for the Cancer and AIDS Registry Linkage Study}

'Senvizio di Epidemiologia e Biostatistica, Centro di Riferimento Oncologico IRCCS, via Pedemontana Occ. le 12, 3308I Aviano (PN), Italy; ${ }^{2}$ International Agency for Reserch on Cancer, 150 Cours A. Thomas, 69372 Lyon Cedex 08, France; ${ }^{3}$ Dipartimento di Epidemiologia, IRCCS 'L. Spallanzani', via Portuense, 292, 00149 Rome, Italy; ${ }^{4}$ Registro Tumori Toscano, Epidemiologia Clinica e Descrittiva, CSPO Istituto Scientifico Regione Toscana, via S. Salvi, 12, 50135 Florence, Italy; ${ }^{5}$ Registro Tumori della Romagna, Divisione Oncologia Medica, Istituto Oncologico Romagnolo, via Forlanini, II, 47 I 00 Forli, Italy; ${ }^{6}$ Registro Tumori del Veneto, Azienda Ospedaliera di Padova, via Gattamelata, 64, 35 I 28 Padua, Italy; ${ }^{7}$ Registro Tumori Piemonte, via S. Francesco da Paola, 31, 10123 Turin, Italy; ${ }^{8}$ Dipartimento Oncologia: Biologiae Genetica, Università di Genova, Registro Tumori e Mortalità Regione Liguria, L.go Rosanna Benzi, 10, 16132 Genoa, Italy; ${ }^{9}$ Centro Operativo AIDS, Istituto Superiore di Sanità, via Regina Elena, 299, 00161 Rome, Italy

A record linkage was carried out between the Italian Registry of AIDS and 19 Cancer Registries (CRs), which covered 23\% of the Italian population, to estimate the overall cancer burden among persons with HIV or AIDS (PWHA) in Italy, according to various characteristics. Observed and expected numbers of cancer and standardised incidence ratios (SIRs) were assessed until 1998 in 12 I 04 PWHA aged 15-69 years, for a total of 6042 I person-years. Significantly increased SIRs were observed for Kaposi's sarcoma (KS, 1749-fold higher than the general population), non-Hodgkin's lymphomas (NHL, 352), and invasive cervical cancer (22). SIR was significantly elevated also for cancer of the anus (34), lung cancer (2.4), brain tumours (4.4), Hodgkin's disease (16), and leukaemias (5.3). The majority of lung and brain cancers were not histologically confirmed, and the possibility of misclassification with $\mathrm{KS}$ or $\mathrm{NHL}$ cannot be ruled out. The SIR for all non-AIDS-defining cancers was 2.2 in men and 2.5 in women. Intravenous drug users showed significantly more elevated SIRs for lung cancer (9.4), and brain tumours (6.7) than other transmission categories (SIR $=1.4$ and 2.3, respectively). This study confirmed increased SIRs for haemolymphopoietic neoplasms other than NHL in PWHA, although manyfold smaller than for NHL. An association with human papillomavirus-related cancers was also confirmed.

British Journal of Cancer (2003) 89, 94-100. doi:10.1038/sj.bjc.6601017 www.bjcancer.com

(C) 2003 Cancer Research UK

Keywords: AIDS; epidemiology; haemolymphopoietic neoplasms; papillomavirus

Since the mid-1990s, cancer incidence in persons with HIV or AIDS (PWHA) has been investigated by a few large populationbased linkage studies of AIDS and cancer registries (CRs) in the United States (Goedert et al, 1998), Europe (Franceschi et al, 1998a), and Australia (Grulich et al, 2002). These studies have provided essential information on the frequency and characteristics of cancers in the course of HIV infection.

In comparison with the general population, PWHA show a thousand-fold elevated risk of developing Kaposi's sarcoma (KS) and a hundred-fold higher risk of non-Hodgkin's lymphoma (NHL) (IARC, 1996; Dal Maso et al, 2001c) Increases have also been reported for other cancer types, such as squamous carcinomas of the anus, invasive cervical cancer (ICC), skin, conjunctiva, and Hodgkin's disease (Franceschi et al, 1998a; Frisch et al, 2001; Grulich et al, 2002). Since most of these malignancies are driven by oncogenic viruses, cancer excess in PWHA is likely to be the combined effect of HIV and infections other than HIV (Boshoff and Weiss, 2002). Excesses of neoplasms, such as cancer of the lung, testis, and liver, have been reported less consistently

\footnotetext{
*Correspondence: Dr L Dal Maso, E-mail: epidemiology@cro.it

"The participants of the Cancer and AIDS Registry Linkage study are listed in the Appendix.

Received 27 January 2003; revised 18 March 2003; accepted 28 March 2003
}

(IARC, 1996; Frisch et al, 2001). Finally, in all developed countries, the introduction of the highly active antiretroviral therapies (HAART) in the mid-1990s has greatly modified the natural history of AIDS but, except for the decline in KS incidence, the effect of HAART on cancer incidence in PWHA remains unclear (International Collaboration on HIV and Cancer, 2000).

Italy offers an interesting research opportunity with respect to such issues since the AIDS epidemic has grown faster, women constitute a large proportion of PWHA (Dal Maso et al, 1995; Pezzotti et al, 1999; ENAADS, 2000), and validated AIDS surveillance programme covers the whole population while CRs cover nearly a quarter of the population.

We have updated our previous study, including twice as many person-years (Franceschi et al, 1998a). The purpose is to estimate the cancer burden among PWHA in Italy overall and according to time since AIDS and selected characteristics.

\section{MATERIALS AND METHODS}

The general design of our record linkage study has been described previously (Franceschi et al, 1998a, b). In brief, notification of AIDS cases from all over Italy to the AIDS Registry (RAIDS) in Rome was initiated on a voluntary basis in 1982 and became mandatory in November 1986. At the end of 2000, a total of 47503 AIDS cases had been reported (ISS, 2001). A linkage of RAIDS data 
and death certificates in 1992 suggested that under-reporting of AIDS cases in Italy was less than $10 \%$ (Conti et al, 1997), that is, one of the lowest percentages of under-reporting in Europe (Ajdacic-Gross et al, 2001).

In all, 19 independent CRs were active in Italy in the mid-1990s, covering a population of 12.7 million, corresponding to $23 \%$ of the total Italian population. They served the regions of Romagna, Friuli-Venezia Giulia, Umbria, and part of Veneto region, the municipality of Turin, the provinces of Genoa, Biella, Varese, Parma, Modena, Ferrara, Macerata, Florence and Prato, Sassari, Trento, Bolzano (Alto Adige), Ragusa, Latina, and part of the province of Naples (Zanetti et al, 2002; Parkin et al, 2002). Cancer Registeries varied both in size, ranging from approximately 190000 to nearly 1.9 million of population covered, and in number of registration years available. Routine indicators of data completeness and quality in Italian CRs were satisfactory (Parkin et al, in press, 1997; Zanetti et al, 2002).

An 'ad hoc' software application was developed to perform the record linkage procedure (Dal Maso et al, 2001c). Briefly, records from RAIDS and CRs were linked by last and first name, and by date of birth. Satisfaction of name-date algorithm required: (a) that the records were identical for at least one critical field, and (b) that the other two critical fields, if not identical, differed only in prescribed ways. Since the system operated under procedures that removed all personal identifiers, the staffs of each type of registry were blinded to which persons had been linked.

The present study was restricted to people who: (1) were aged between 15 and 69 years at the time of AIDS diagnosis; (2) reported a legal residence in areas covered by CRs; (3) were diagnosed with cancer in periods deemed complete at both registries (i.e. in most instances through to the end of 1998); and (4) were diagnosed with AIDS after 1985, since no cancer case among PWHA had been reported earlier.

AIDS-defining cancers (i.e. KS, NHL and, since 1993, ICC) are also reported to RAIDS, but only notification of neoplasms to CRs were included in the present analysis for the sake of comparability with non-AIDS defining cancers (NADC). In situ carcinoma of the cervix and other preneoplastic lesions (e.g. behaviour code 0-2) (WHO, 1990) were excluded from the present analysis because of incomplete reporting in CRs.

Cancers at CRs were identified according to International Classification of Diseases, 9th revision (WHO, 1977) and International Classification of Diseases for Oncology (ICDO) (WHO, 1990). Cases were subsequently recoded according to International Classification of Disease, 10th revision (WHO, 1992). Cancers were further subdivided according to whether histological, haematological, or cytological confirmation (henceforth referred to as histological confirmation) was available or diagnosis had been made otherwise (i.e. clinical, instrumental diagnosis, etc.). Cancer Registry coordinators reviewed all records on histological type and site of cancers.

When an AIDS-defining cancer was mentioned in both RAIDS and $\mathrm{CR}$, date of cancer diagnosis was defined as the earliest one. When KS, NHL, or ICC (after 1993) was reported in the CR up to 5 years prior to the date of AIDS diagnosis in RAIDS, the date of AIDS onset was backdated.

Person-years at risk were computed only between 5 years prior to AIDS diagnosis (in order to exclude cancer diagnosis which may have occurred before HIV infection) and date of death or 3.5 years after AIDS diagnosis, whichever occurred earlier, to reduce inaccuracies from losses at follow-up. This interval was left- or right-censored if no complete $C R$ data were available in the corresponding years. Expected numbers of different cancer sites or types were computed in each CR from sex- and age-specific (5 years) incidence rates (Parkin et al, 2002, 1997, 1992) in four periods: early pre-AIDS (from -60 to -25 months), late pre-AIDS (from -24 to -7 months), AIDS period (from -6 to +3 months), and post-AIDS period (from +4 to +42 months). Observed numbers of cancer in PWHA were compared to expected numbers by means of standardised incidence ratios (SIRs). Corresponding 95\% confidence intervals (CI) were computed using the Poisson distribution (Breslow and Day, 1987).

\section{RESULTS}

Overall, 12104 AIDS cases (78\% men and 22\% women) were reported in areas covered by one of the $19 \mathrm{CRs}$ (Table 1) for a total of 60421 person-years (Table 2). In all, 70\% of person-years referred to the periods prior to AIDS diagnosis. The majority of PWHA enrolled in this study were intravenous drug users (IDUs, $62 \%$ ), and the median age was 33 years. Between 5 years before AIDS diagnosis and 3.5 years thereafter, 170 cancers other than KS, NHL, and ICC were identified (Table 1). Using only cancer information from CRs, the numbers were 525 for KS, 449 for NHL, and 18 for ICC.

Table 2 shows observed and expected numbers and corresponding SIRs for cancer sites or types with at least two cases observed. As expected, high SIRs were found for KS (1749; 95\% CI: $1602-$ 1905), NHL (352; 95\% CI: 320-386), and, to a lesser extent, ICC (22; 95\% CI: 13-35). All ICC were squamous-cell carcinomas.

The combination of NADC showed a SIR of 2.3 (95\% CI: $2.0-$ 2.7). Significantly elevated SIRs were seen for cancer of the anus (34; 95\% CI: $12-74)$, lung (2.4; 95\% CI: $1.5-3.7)$, brain $(4.4 ; 95 \%$ CI: $2.2-8.0)$, Hodgkin's disease (HD) (16; 95\% CI: 12-22), and leukaemias $(5.3 ; 95 \% \mathrm{CI}: 2.8-9.2)$. In respect to time of cancer diagnosis, all sites and types showed the highest SIR in the AIDS period and a compensatory fall in SIR after AIDS. Risk excess before AIDS was seen for ICC and cancer of the anus, and for HD and leukaemias.

Anal cancers (six cases) included five squamous-cell carcinomas and one cloacogenic carcinoma.

Only 12 out of 22 lung cancers were histologically confirmed, including five squamous-cell carcinoma, two adenocarcinoma, and one each of five other histologies. In four out of 10 nonhistologically confirmed lung cancer cases, lung lesions of infectious origin, such as pneumocystis carinii pneumonia, were reported at RAIDS. None of the 11 brain cancers were histologically confirmed, eight had occurred in the AIDS period, and three had a concurrent diagnosis of cerebral toxoplasmosis or HIV encephalopathy at RAIDS. The proportions of histologically confirmed cancers among PWHA (79\%) were similar to the proportion in the general population of the same CRs $(80 \%)$. Restricting the analysis to cancers with histological confirmation, the SIR was 1.7 (95\% CI: 1.4-2.1) for the combination of all NADC. The greater reduction in SIR, after the exclusion of unconfirmed cases, was noted for cancer of the lung $(\operatorname{SIR}=1.3)$ and brain $(\mathrm{SIR}=0.0)$ (not shown).

Among $45 \mathrm{HDs}$, the histological type was mixed cellularity in 19 subjects and nodular sclerosis in 13. The other HDs were of lymphocytic predominance (one), lymphocytic depletion (three), and unspecified type (nine).

The cancer sites or types that showed a significant excess in PWHA or were observed in more than 10 individuals were reexamined in separate strata of gender, age, and HIV-exposure category (Table 3$)$. Standardised incidence ratios were higher in women than in men for KS (2717 vs 1696, respectively), NHL (538 $v s 321)$, and cancer of the lung (8.7 vs 2.2). For the combination of all NADS, no difference emerged between genders $(\mathrm{SIR}=2.2$ and 2.5 in men and women, respectively). The age distribution varied by cancer type: median age was 37 years for KS (range: 19-68), 33 years for NHL $(21-68), 35$ years for ICC $(37-48), 42$ years for anal cancer (34-55), 39 years for lung cancer (23-68), 50 years for non-melanomatous skin cancer (36-69), 31 years for brain cancer $(28-58), 32$ years for HD (19-43), and 32 years for leukaemias $(21-67)$. Standardised incidence ratios tended to be higher in the 
Table I AIDS diagnoses and linked cases by type of cancer in 19 Italian areas covered by Cancer Registries (CRs)

\begin{tabular}{|c|c|c|c|c|c|c|c|c|}
\hline \multirow[b]{2}{*}{ CR } & \multirow[b]{2}{*}{ Complete period } & \multirow{2}{*}{$\begin{array}{l}\text { Population } \\
(\times 1000)\end{array}$} & \multirow[b]{2}{*}{ Cancer cases } & \multirow{2}{*}{$\begin{array}{l}\text { AIDS cases } \\
\text { in CR areas } \\
(1982-2000)\end{array}$} & \multicolumn{4}{|c|}{ 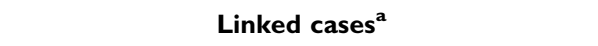 } \\
\hline & & & & & KS & NHL & ICC & Other cancers \\
\hline Alto Adige & $1995-97$ & 453 & 8107 & 196 & 4 & 2 & 0 & 3 \\
\hline Biella & $1995-98$ & 190 & 5782 & 253 & 3 & 6 & I & I \\
\hline Ferrara & $1989-98$ & 361 & 32749 & 379 & 14 & 18 & 0 & 3 \\
\hline Florence & $1985-97$ & |07| & 97506 & 1050 & 100 & 58 & I & 29 \\
\hline FVG & $1995-98$ & 1186 & 40002 & 379 & 6 & 4 & 0 & 1 \\
\hline Genoa & $1985-96$ & 679 & 76746 & 1566 & 59 & 51 & 4 & 22 \\
\hline Latina & $1983-98$ & 527 & 21630 & 337 & 5 & 9 & I & I \\
\hline Macerata & $199 \mid-97$ & 358 & 12773 & 112 & 6 & 2 & 1 & 0 \\
\hline Modena & $1988-98$ & 620 & 42681 & 543 & 32 & 21 & 2 & 6 \\
\hline Naples & $1996-98$ & 525 & 4655 & 94 & I & 2 & 0 & 0 \\
\hline Parma & $1982-98$ & 391 & 27745 & 308 & 17 & 13 & 0 & 7 \\
\hline Ragusa & $1982-97$ & 313 & 16892 & 53 & 2 & 1 & 0 & I \\
\hline Romagna & $1985-97$ & 433 & $7 \mid 553$ & 1485 & 63 & 64 & 2 & 22 \\
\hline Sassari & $1992-97$ & 468 & | | 883 & 302 & 7 & 12 & 0 & 3 \\
\hline Trento & $1995-98$ & 455 & | | 756 & 284 & 5 & 8 & 0 & 4 \\
\hline Turin & $1985-98$ & 963 & 85751 & 1106 & 83 & 37 & 1 & 25 \\
\hline Umbria & $1994-97$ & 911 & 27745 & 372 & 14 & 19 & 0 & 4 \\
\hline Varese & $1982-97$ & 789 & 54400 & 1462 & 39 & 66 & 3 & 14 \\
\hline Veneto & $1987-96$ & 1890 & 121347 & 1823 & 65 & 56 & 2 & 23 \\
\hline Total & & 12583 & 698380 & 12104 & 525 & 449 & 18 & 170 \\
\hline
\end{tabular}

KS = Kaposi's sarcoma; NHL = non-Hodgkin lymphoma; ICC = invasive cervical cancer; FVG = Friuli-Venezia Giulia

${ }^{a}$ Cancers notified at CRs in people with AIDS, age 15-69 years, between 1985 and 1998 from 5 years prior to 3.5 years after an AIDS diagnosis.

15-34-year age group than in the 35-69-year age group for all cancer sites, except for KS and cancers of the cervix uteri and anus. Standardised incidence ratios were also higher among IDUs than other HIV exposure category for all cancer types except for KS and leukaemias. Standardised incidence ratio for KS and anal cancer was particularly high among homosexual and bisexual men (6066 and 56, respectively).

The risk of NADCs in PWHA at or after AIDS diagnosis (patients who were likely to take advantage of HAART) did not diminish between pre-HAART $(\mathrm{SIR}=4.7)$ and post-HAART period (SIR $=5.7)$. Moreover, no statistically significant change emerged for any specific cancer site or type of NADCs (data not shown).

\section{DISCUSSION}

Cancers of the anus, brain, lung, HD, and leukaemias, in addition to AIDS-defining cancers (KS, NHL, and ICC), have been found in our study to be significantly increased in PWHA.

As in previous studies (Franceschi et al, 1998a; Sitas et al, 2000; Grulich et al, 2002; Frisch et al, 2001), the group of NADCs, which showed the most consistent excess in PWHA was lymphohaematopoietic cancers. HD risk, among PWHA, was more than 10-fold increased in every strata of gender, age, and HIV-exposure category. An association between HD and HIV infection is, hence, well established (Dal Maso and Franceschi, 2003). An excess of leukaemias and myeloma is also suggested by our present findings.

Histological confirmation was available for almost all HDs (43 out of 45), myelomas (three out of three), and leukaemias (10 out of 13) in our study. A misdiagnosis of NHL as other haemolymphopoietic neoplasms cannot be totally ruled out because the classification of haemolymphopoietic neoplasms in PWHA is especially difficult (Carbone, 2002). Some leukaemias might be leukaemoid transformations of AIDS-related NHL. The SIR for lymphoid leukaemia was not significantly greater than the one for myeloid leukaemia, in agreement with the findings by Frisch et al (2001) in the United States.
As in previous reports (Andrieu et al, 1993; Serraino et al, 1993), the most common subtype of HD in PWHA was mixed cellularity type. Nodular sclerosis type (i.e. the commonest HD type in the general population of an age comparable to PWHA) was relatively rare. Besides being more aggressive and more frequently involving bone marrow, HD in PWHA seems to be associated with EBV more often than in the general population (Tirelli et al, 2000).

Other cancers whose SIRs were found to be consistently elevated in PWHA are those associated with HPV infection (IARC, 1995). In contrast to KS and NHL, ICC has been an AIDS defining disease only since 1993 (Ancelle Park, 1993). We were, therefore, able to observe some ICC cases prior to AIDS and noticed that, although SIR peaked in the AIDS period as for all other sites and types, some excess was present years before AIDS. A similar time pattern was found for anal cancer, whose overall SIR (34) was well comparable to the one seen for ICC. Three additional cases of cancer of the vulva, penis, and uterus (not otherwise specified) further support the possibility that HIV-induced immune impairment facilitates the persistence of HPV infection (Palefsky et al, 1999; Ahdieh et al, 2000): progression into pre-malignant (Sun et al, 1997) and, ultimately, in the lack of early detection, invasive cancer. As suggested also by studies where preinvasive lesions of the cervix and anogenital tract were included (Frisch et al, 2000), the control of HPV infections seems to be impaired in HIV-positive women and men years before a diagnosis of AIDS. Early events in HPV carcinogenesis are probably affected to a greater extent than late ones (i.e. invasiveness). The SIR for cancer of the cervix and anus was marginally greater but not restricted to specific HIV exposure categories (i.e. IDUs and homosexual and bisexual men, respectively). Since HPV and HIV share a sexual route of transmission, it has been considered difficult to disentangle their independent contribution to the increase in risk of anogenital cancer in PWHA (Mandelblatt et al, 1999). A majority of sexually active women (Woodman et al, 2001) and men (Franceschi et al, 2002), however, at some point in their lifetime are infected by HPV. Therefore, factors that enhance the probability of HPV infection becoming persistent and progress into premalignant and malignant lesions are crucial (IARC 1995). In particular, a lack of cytotoxic T- 
Table 2 Observed (Obs) and expected (Exp) numbers of cancers in person HIV or with AIDS, SIR, and corresponding $95 \% \mathrm{Cl}$ by time of diagnosis and overall. Italy, I985- I998

\begin{tabular}{|c|c|c|c|c|c|c|c|c|c|c|c|c|c|c|c|c|}
\hline \multirow[b]{2}{*}{ ICDI0, cancer type or site } & \multicolumn{3}{|c|}{$\begin{array}{l}60-25 \text { months } \\
\text { before AIDS }\end{array}$} & \multicolumn{3}{|c|}{$\begin{array}{l}24-7 \text { months } \\
\text { before AIDS }\end{array}$} & \multicolumn{3}{|c|}{$\begin{array}{l}6 \text { months before to } \\
3 \text { months after AIDS }\end{array}$} & \multicolumn{3}{|c|}{$\begin{array}{l}\text { 4-42 months } \\
\text { after AIDS }\end{array}$} & \multicolumn{4}{|c|}{ Total } \\
\hline & Obs & SIR & $(95 \% \mathrm{Cl})$ & Obs & SIR & $(95 \% \mathrm{Cl})$ & Obs & SIR & $(95 \% \mathrm{Cl})$ & Obs & SIR & $(95 \% \mathrm{Cl})$ & Obs & Exp & SIR & $(95 \% \mathrm{Cl})$ \\
\hline Person years & \multicolumn{3}{|c|}{27882} & \multicolumn{3}{|c|}{14652} & \multicolumn{3}{|c|}{7491} & \multicolumn{3}{|c|}{10397} & \multicolumn{4}{|c|}{60421} \\
\hline $\mathrm{C} 46, \mathrm{KS}$ & & & & & & & 406 & 6667 & $(6034-7348)$ & 119 & 497 & $(412-595)$ & 525 & 0.30 & 1749 & $(1602-1905)$ \\
\hline $\mathrm{C} 82-\mathrm{C} 85, \mathrm{NHL}$ & & & & & & & 322 & 1229 & $(1098-137 \mid)$ & 127 & 125 & $(105-149)$ & 449 & 1.27 & 352 & $(320-386)$ \\
\hline C53, ICC & 1 & 3.0 & $(0.0-17.5)$ & 2 & 9.6 & $(0.9-35.4)$ & 14 & 121.2 & $(66-204)$ & I & 5.8 & $(0.0-33.1)$ & 18 & 0.82 & 21.8 & $(12.9-34.6)$ \\
\hline $\mathrm{Cl}$ 6, Stomach & 1 & 0.6 & $(0.0-3.7)$ & I & 1.1 & $(0.0-6.2)$ & 4 & 8.1 & $(2.1-21.1)$ & 2 & 3.3 & $(0.3-12.2)$ & 8 & 3.56 & 2.2 & $(1.0-4.4)$ \\
\hline $\mathrm{Cl}$, Colon & 0 & 0 & - & 2 & 1.8 & $(0.2-6.6)$ & 1 & 1.6 & $(0.0-9.4)$ & । & 1.3 & $(0.0-7.5)$ & 4 & 4.21 & 0.9 & $(0.2-2.5)$ \\
\hline C20, Rectum & 0 & 0 & - & I & 1.7 & $(0.0-10.0)$ & 2 & 6.5 & $(0.6-23.9)$ & 2 & 5.2 & $(0.5-19.0)$ & 5 & 2.18 & 2.3 & $(0.7-5.4)$ \\
\hline C2I, Anus & 3 & 44.4 & $(8.4-131.4)$ & 0 & 0 & - & 1 & 38.5 & $(0.0-220.9)$ & 2 & 51.5 & $(4.9-189.2)$ & 6 & 0.18 & 33.6 & $(12.1-73.6)$ \\
\hline C22, Liver & 0 & 0 & - & 0 & 0 & - & 1 & 4.3 & $(0.0-24.6)$ & 2 & 6.9 & $(0.7-25.5)$ & 3 & 1.58 & 1.9 & $(0.4-5.6)$ \\
\hline C25, Pancreas & 0 & 0 & - & 0 & 0 & - & i & 5.5 & $(0.0-31.4)$ & I & 4.4 & $(0.0-25.1)$ & 2 & 1.27 & 1.6 & $(0.1-5.8)$ \\
\hline C32, Larynx & 0 & 0 & - & 0 & 0 & - & I & 3.7 & $(0.0-21.0)$ & I & 3.0 & $(0.0-17.3)$ & 2 & 1.95 & 1.0 & $(0.1-3.8)$ \\
\hline C33-C34, Trachea and lung & 1 & 0.3 & $(0.0-1.5)$ & 0 & 0 & - & 13 & 10.3 & $(5.5-17.7)$ & 8 & 5.4 & $(2.3-10.8)$ & 22 & 9.02 & 2.4 & $(1.5-3.7)$ \\
\hline C43, Melanoma & 0 & 0 & - & 1 & 1.1 & $(0.0-6.1)$ & 2 & 3.9 & $(0.4-14.3)$ & 0 & 0 & - & 3 & 3.72 & 0.8 & $(0.2-2.4)$ \\
\hline C44, Skin & 3 & 0.8 & $(0.2-2.4)$ & 5 & 2.1 & $(0.7-4.9)$ & 3 & 2.3 & $(0.4-6.7)$ & 3 & 1.7 & $(0.3-4.9)$ & 14 & 9.28 & 1.5 & $(0.8-2.5)$ \\
\hline C50, Breast ${ }^{b}$ & 0 & 0 & - & 3 & 2.6 & $(0.5-7.8)$ & 0 & 0 & - & 0 & 0 & - & 3 & 4.43 & 0.7 & $(0.1-2.0)$ \\
\hline C56, Ovary & 0 & 0 & - & 0 & 0 & - & 3 & 33.1 & $(6.2-98.1)$ & 0 & 0 & - & 3 & 0.68 & 4.4 & $(0.8-13.2)$ \\
\hline C61, Prostate & 0 & 0 & - & 1 & 2.1 & $(0.0-\mid 1.8)$ & 0 & 0 & - & 1 & 3.1 & $(0.0-17.6)$ & 2 & 1.72 & 1.2 & $(0.1-4.3)$ \\
\hline C62, Testis & 0 & 0 & - & 4 & 4.3 & $(1.1-11.2)$ & 0 & 0 & - & 0 & 0 & - & 4 & 3.73 & 1.1 & $(0.3-2.8)$ \\
\hline C64, Kidney & 1 & 0.9 & $(0.0-5.0)$ & 1 & 1.4 & $(0.0-8.0)$ & 1 & 2.6 & $(0.0-14.8)$ & 0 & 0 & - & 3 & 2.75 & 1.1 & $(0.2-3.2)$ \\
\hline C67, Bladder & 0 & 0 & - & I & 0.8 & $(0.0-4.5)$ & 0 & 0 & - & I & 1.2 & $(0.0-7.0)$ & 2 & 4.80 & 0.4 & $(0.0-1.5)$ \\
\hline C70-C72, Brain & 0 & 0 & - & 0 & 0 & - & 8 & 24.3 & $(\mid 0.4-48.0)$ & 3 & 6.6 & $(1.2-19.5)$ & 11 & 2.48 & 4.4 & $(2.2-8.0)$ \\
\hline C81, Hodgkin's disease & 6 & 4.6 & $(1.6-10.0)$ & 12 & 17.9 & $(9.2-31.4)$ & 19 & 56.3 & $(33.8-88.1)$ & 8 & 17.6 & $(7.5-34.8)$ & 45 & 2.77 & 16.2 & $(11.8-21.7)$ \\
\hline C90, Myeloma & 0 & 0 & - & 1 & 6.0 & $(0.0-34.5)$ & 0 & 0 & - & 2 & 16.6 & $(1.6-61.0)$ & 3 & 0.62 & 4.8 & $(0.9-14.3)$ \\
\hline C91-C95, Leukaemia, all & 1 & 0.9 & $(0.0-5.4)$ & 3 & 4.9 & $(0.9-14.4)$ & 6 & 18.5 & $(6.7-40.5)$ & 3 & 6.9 & $(1.3-20.4)$ & 13 & 2.44 & 5.3 & $(2.8-9.2)$ \\
\hline C9I, Leukaemia, lymphoid & 1 & 2.7 & $(0.0-15.2)$ & 0 & 0 & - & 4 & 34.0 & $(8.8-87.8)$ & 0 & 0 & - & 5 & 0.87 & 5.7 & $(1.8-13.5)$ \\
\hline C92, Leukaemia, myeloid & 0 & 0 & - & 2 & 5.7 & $(0.5-21.0)$ & 1 & 5.4 & $(0.0-30.9)$ & 2 & 7.9 & $(0.7-29.2)$ & 5 & 1.39 & 3.6 & $(1.1-8.4)$ \\
\hline All non-AIDS defining cancer ${ }^{c}$ & 18 & 0.6 & $(0.3-0.9)$ & 39 & 2.0 & $(1.4-2.8)$ & 68 & 6.6 & $(5.1-8.4)$ & 45 & 3.3 & $(2.4-4.5)$ & 170 & 74.48 & 2.3 & $(2.0-2.7)$ \\
\hline
\end{tabular}

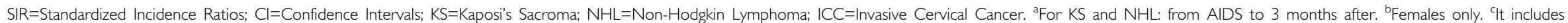

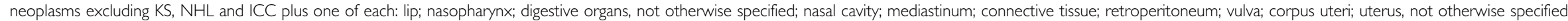
penis; endocrine glands; and unknown primary site. 
Table 3 Observed cases (Obs) of selected cancers, SIR and corresponding 95\% Cl among people with HIV or AIDS by gender, age group, and HIV exposure category, Italy, $1985-1998$

\begin{tabular}{|c|c|c|c|c|c|c|c|c|c|c|c|c|}
\hline \multirow{2}{*}{$\begin{array}{l}\text { ICDIO-cancer } \\
\text { type or site }\end{array}$} & \multicolumn{4}{|c|}{ Gender } & \multicolumn{4}{|c|}{ Age group } & \multicolumn{4}{|c|}{$\begin{array}{l}\text { HIV exposure } \\
\text { category }\end{array}$} \\
\hline & \multicolumn{2}{|r|}{ Men } & \multicolumn{2}{|r|}{ Women } & \multicolumn{2}{|r|}{$15-34$} & \multicolumn{2}{|r|}{$35-69$} & \multicolumn{2}{|r|}{ IDU } & \multicolumn{2}{|c|}{ Other } \\
\hline C46: KS & 483 & $\begin{array}{l}1696 \\
(1548-1854)\end{array}$ & 42 & $\begin{array}{c}2717 \\
(1957-3675)\end{array}$ & 228 & $\begin{array}{c}1218 \\
(1065-1387)\end{array}$ & 297 & $\begin{array}{c}2628 \\
(2337-2945)\end{array}$ & 115 & $\begin{array}{c}557 \\
(460-669)\end{array}$ & $410^{\mathrm{a}}$ & $\begin{array}{c}4369 \\
(3956- \\
4813)\end{array}$ \\
\hline C53: ICC & - & - & 18 & $\begin{array}{c}21.8 \\
(12.9-34.6)\end{array}$ & 8 & $\begin{array}{c}23.4 \\
(10.0-46.4)\end{array}$ & 10 & $\begin{array}{c}20.7 \\
(9.9-38.2)\end{array}$ & 11 & $\begin{array}{c}24.0 \\
(11.9-43.1)\end{array}$ & 7 & $\begin{array}{c}19.1 \\
(7.6-39.6)\end{array}$ \\
\hline C21: anus & 5 & $\begin{array}{c}35.1 \\
(11.1-82.5)\end{array}$ & । & $\begin{array}{c}27.6 \\
(0.0-158.3)\end{array}$ & I & $\begin{array}{c}31.3 \\
(0.0-179.3)\end{array}$ & 5 & $\begin{array}{c}34.1 \\
(10.8-80.2)\end{array}$ & 2 & $\begin{array}{c}33.6 \\
(3.2-123.6)\end{array}$ & $4^{b}$ & $\begin{array}{c}33.6 \\
(8.7-86.8)\end{array}$ \\
\hline C33, C34: trachea and lung & 19 & $\begin{array}{c}2.2 \\
(1.3-3.4)\end{array}$ & 3 & $\begin{array}{c}8.7 \\
(1.6-25.9)\end{array}$ & 6 & $\begin{array}{c}19.4 \\
(7.0-42.4)\end{array}$ & 16 & $\begin{array}{c}1.8 \\
(1.0-3.0)\end{array}$ & 11 & $\begin{array}{c}9.4 \\
(4.6-16.8)\end{array}$ & 11 & $\begin{array}{c}1.4 \\
(0.7-2.5)\end{array}$ \\
\hline C8I: Hodgkin's disease & 36 & $\begin{array}{c}16.7 \\
(11.7-23.1)\end{array}$ & 9 & $\begin{array}{c}14.6 \\
(6.6-27.9)\end{array}$ & 33 & $\begin{array}{c}17.9 \\
(12.3-25.2)\end{array}$ & 12 & $\begin{array}{c}12.9 \\
(6.7-22.7)\end{array}$ & 34 & $\begin{array}{c}18.1 \\
(12.5-25.3)\end{array}$ & 11 & $\begin{array}{c}12.3 \\
(6.1-22.1)\end{array}$ \\
\hline C91-C95: leukaemias & 12 & $\begin{array}{c}5.7 \\
(2.9-10.1)\end{array}$ & । & $\begin{array}{c}2.9 \\
(0.0-16.7)\end{array}$ & 8 & $\begin{array}{c}8.4 \\
(3.6-16.7)\end{array}$ & 5 & $\begin{array}{c}3.4 \\
(1.1-7.9)\end{array}$ & 5 & $\begin{array}{c}4.3 \\
(1.3-10.0)\end{array}$ & 8 & $\begin{array}{c}6.3 \\
(2.7-12.6)\end{array}$ \\
\hline All non-AIDS defining Cancers & 135 & $\begin{array}{c}2.2 \\
(1.9-2.7)\end{array}$ & 35 & $\begin{array}{c}2.5 \\
(1.7-3.4)\end{array}$ & 74 & $\begin{array}{c}4.6 \\
(3.6-5.8)\end{array}$ & 96 & $\begin{array}{c}1.6 \\
(1.3-2.0)\end{array}$ & 87 & $\begin{array}{c}3.6 \\
(2.9-4.4)\end{array}$ & 83 & $\begin{array}{c}1.7 \\
(1.3-2.1)\end{array}$ \\
\hline
\end{tabular}

$\mathrm{SIR}=$ Standardized Incidence Ratios; $\mathrm{Cl}=$ Confidence Intervals; KS=Kaposi's Sacroma; NHL=Non-Hodgkin Lymphoma; ICC=Invasive Cervical Cancer. IDU = Intravenous drug user ${ }^{\mathrm{a}} 310$ cases among homosexual and bisexual men, SIR =6066, 95\% Cl: 5409-6780. ${ }^{\mathrm{b}}$ Three cases among homosexual and bisexual men, SIR = 56.4, 95\% Cl: I0.6- I67.0.

lymphocyte to the early (E) oncoprotein six antigen is associated with persistence of HPV infection (Tindle, 2002).

Nonmelanomatous skin cancer showed a three-fold excess in PWHA in our previous report (Franceschi et al, 1998a), whereas a somewhat lower SIR (1.5; 95\% CI: 0.8-2.5) emerged from our present update. Misclassification with KS seems unlikely, since all nonmelanomatous skin cancers in PWHA were histologically confirmed (seven squamous-cell and seven basal-cell carcinomas). The report of nonmelanomatous skin cancer to CRs is, however, incomplete (Levi et al, 1995; Parkin et al, 1997) and the corresponding SIR must be interpreted cautiously. No data on nonmelanomatous skin cancer are available from North American (Frisch et al, 2001) and Australian (Grulich et al, 2002) record linkage studies. Gallagher et al (2001) reported a 10-fold increased SIR of cancer of the lip in New York State and several authors (Frisch et al, 2001; Grulich et al, 2002) showed a two- to- four-fold increased risk. Interestingly, skin cancer in our study affected more frequently older PWHA than any other NADC.

Cancers of the lung and brain are found to be consistently increased among PWHA, but masses of non-neoplastic origin or attributable to NHL are common in the lung and brain at AIDS diagnosis. These masses may be misdiagnosed as cancer of the lung or brain, particularly in the absence of histological confirmation. Interestingly, lung cancer showed the most marked variation by HIV transmission group among NADCs. As in Serraino et al (1997, 2000), lung cancer seemed restricted to IDUs, among whom smoking levels are much higher than in the general population.

Hepatocellular carcinoma is another cancer type aetiologically related to viruses (i.e. hepatitis B and $C$ viruses) that, in turn, share the same route of transmission of HIV and have a high prevalence in PWHA (Smukler and Ratner, 2002). However, our present study showed only a moderate excess $(\mathrm{SIR}=1.9)$ of HCC in agreement with other authors (Frisch et al, 2001; Gallagher et al, 2001; Grulich et al, 2002). It is possible that, until recently, PWHA have not survived long enough to allow the carcinogenic effect of hepatitis viruses to manifest (Deuffic et al, 1999).

Standardised incidence ratios were above unity for a few additional cancer types (i.e. stomach, rectum, and ovary), but corresponding CI were broad, due to the relatively small number of cases observed.

No reduction in the SIR of NADCs emerged in Italy after the introduction of HAART. Our present study is based, however, on too short a period after HAART to allow any conclusion.

The validity of cohorts defined by AIDS diagnosis, as in record linkage studies, to estimate risks of NADCs before AIDS has been questioned (Goedert et al, 1998; International Collaboration on HIV and Cancer, 2000). Li et al (2002), however, have recently demonstrated that in Australia one cohort based on AIDS diagnosis and two based on HIV diagnosis provided consistent SIRs for the 10 commonest NADCs.

Since a large number of NADCs occurs before AIDS, the major strength of such methodology is represented by the access to a large number of person-years of observation both before and after AIDS (Franceschi et al, 1998b; Goedert et al, 1998). The number of PWHA and of cancer diagnoses may be underestimated on account of incompleteness of reporting to either AIDS or CRs or of missed linkages. However, the completeness of RAIDS and Italian CRs had been shown to be satisfactory and the linkage procedures we used had been validated (Conti et al, 1997; AjdacicGross et al, 2001; Dal Maso et al, 2001a). The problem of migration of PWHA out of CR areas should be less severe in Italy than elsewhere, as population mobility is comparatively low and HIV and cancer treatments are available free of charge in all Italian regions (Franceschi et al, 1998b). As already reported (Biggar et al, 1996), SIRs for all cancer sites or types are exaggerated in the 
months immediately before and after AIDS by an increased medical surveillance and some cancers would have been otherwise found later. Our present SIRs in the post-AIDS period are therefore underestimates and this hampers the evaluation of trends in cancer risk by immune status. Cancer excesses were also found, however, prior to AIDS diagnosis, for ICC, cancer of the anus, and HD.

\section{REFERENCES}

Ahdieh L, Muñoz A, Vlahov D, Trimble CL, Timpson LA, Shah K (2000) Cervical neoplasia and repeated positivity of human papillomavirus infection in human immunodeficiency virus-seropositive and -seronegative women. Am J Epidemiol 151: 1148-1157

Ajdacic-Gross V, Zellweger U, Wang J, Fleerackers Y, Somaini B (2001) How complete is AIDS surveillance in Europe? An eagle eye comparison with mortality data. J Epidemiol Commun Health 55: 52-56

Ancelle Park RA (1993) Expanded European AIDS case definition. Lancet 341: 441

Andrieu JM, Roithmann S, Tourani JM, Levy R, Desablens B, le Maignan C, Gastaut JA, Brice P, Raphael M, Taillan B (1993) Hodgkin's disease during HIV1 infection: the French registry experience. Ann Oncol 4: 635-641

Biggar RJ, Rosenberg PS, Coté T, the Multistate AIDS/Cancer Match Study Group (1996) Kaposi's sarcoma and non-Hodgkin's lymphoma following the diagnosis of AIDS. Int J Cancer 68: 754-758

Boshoff C, Weiss R (2002) AIDS-related malignancies. Nat Rev Cancer 2: $373-382$

Breslow NE, Day NE (1987) Statistical Methods in Cancer Research. Vol. II. The Design and Analysis of Cohort Studies, pp 60-71, IARC Sci Publ no 82. Lyon: IARC

Carbone A (2002) AIDS-related non-Hodgkin's lymphomas: from pathology and molecular pathogenesis to treatment. Hum Pathol 33: $392-404$

Conti S, Farchi G, Galletti A, Masocco M, Napoli PA, Pezzotti P, Rezza G, Toccaceli V, Cariani G (1997) La notifica della mortalità per AIDS in Italia (1992): qualità della certificazione e sottonotifica. Giornale Italiano dell'AIDS 8: $12-16$

Dal Maso L, Franceschi S (2003) Epidemiology of non-Hodgkin lymphomas and other haemolymphopoietic neoplasms in people with AIDS. Lancet Oncol 4: 110-119

Dal Maso L, Braga C, Franceschi S (2001a) Methodology used for "Software for Automated Linkage in Italy" (SALI). J Biomed Informatics 34: 387 395

Dal Maso L, Rezza G, Zambon P, Tagliabue G, Crocetti E, Vercelli M, Zanetti R, Falcini F, Tonini G, De Lisi V, Ferretti S, Tumino R, Stanta G, Vitarelli S, Serraino D, Franceschi S (2001b) Non-Hodgkin lymphoma among young adults with and without AIDS in Italy. Int J Cancer 93: $430-435$

Dal Maso L, Serraino D, Franceschi S (2001c) Epidemiology of AIDS-related tumours in developed and developing countries. Eur J Cancer 37: $1188-$ 1201

Dal Maso L, Franceschi S, Negri E, Serraino D, La Vecchia C, Ancelle-Park RA (1995) Trends of AIDS incidence in Europe and the United States. Soz Praventivmed 40: $239-265$

Deuffic S, Buffat L, Poynard T, Valleron A-J (1999) Modeling the hepatitis C virus epidemic in France. Hepatology 29: 1596-1601

ENAADS European Centre for the Epidemiologial Monitoring of AIDS (2000) HIV/AIDS Surveillance in Europe, End-year report 1999, No. 62. Saint-Maurice, France

Franceschi S, Castellsagué X, Dal Maso L, Smith JS, Plummer M, Ngelangel C, Chichareon S, Eluf-Neto J, Shah KV, Snijders PJ, Meijer CJ, Bosch FX, Munoz N (2002) Prevalence and determinants of human papillomavirus genital infection in men. Br J Cancer 86: 705-711

Franceschi S, Dal Maso L, Arniani S, Crosignani P, Vercelli M, Simonato L, Falcini F, Zanetti R, Barchielli A, Serraino D, Rezza G (1998a) Risk of cancer other than Kaposi's sarcoma and non-Hodgkin's lymphoma in persons with AIDS in Italy. $\mathrm{Br} J$ Cancer 78: 966-970

Franceschi S, Dal Maso L, Arniani S, Lo Re A, Barchielli A, Milandri C, Simonato L, Vercelli M, Zanetti R, Rezza G (1998b) Linkage of AIDS and cancer registries in Italy. Int J Cancer 75: 831-834

\section{ACKNOWLEDGEMENTS}

This work was supported by Ministry of Health F.S.N. 2000 Contract No. ICS 060.2/RF 00-55, by three Grants No. 20D/1.1, 20C. 15 and C. 42 from the Istituto Superiore di Sanità, Rome and by ACOV, Naples. We thank Mrs Luigina Mei and Ilaria Calderan for editorial assistance.

Frisch M, Biggar RJ, Engels EA, Goedert JJ, for the AIDS-Cancer Match Registry Study Group (2001) Association of cancer with AIDS-related immunosuppression in adults. JAMA 285: 1736-1745

Frisch M, Biggar RJ, Goedert JJ (2000) Human papillomavirus-associated cancers in patients with human immunodeficiency virus infection and acquired immunodeficiency syndrome. J Natl Cancer Inst 92: $1500-1510$

Gallagher B, Wang Z, Schymura MJ, Kahn A, Fordyce J (2001) Cancer incidence in New York State acquired immunodeficiency syndrome patients. Am J Epidemiol 154: 544-556

Goedert JJ, Coté TR, Virgo P, Scoppa SM, Kingma DW, Gail MH, Jaffe ES, Biggar RJ (1998) Spectrum of AIDS-associated malignant disorders. Lancet 351: $1833-1839$

Grulich A, Li Y, McDonald A, Correll PKL, Law MG, Kaldor JM (2002) Rates of non-AIDS defining cancers in people with HIV infection before and after AIDS diagnosis. AIDS 16: $1155-1161$

IARC Working Group on the Evaluation of Carcinogenic Risks to Humans (1995) IARC Monograph on Evaluating Carcinogenic Risks in Humans Human Papillomaviruses, Vol. 64. Lyon: IARC

IARC Working Group on the Evaluation of Carcinogenic Risks to Humans (1996) IARC Monograph on Evaluating Carcinogenic Risks in Humans Human Immunodeficiency Viruses and Human T-Cell Lymphotropic Viruses, Vol. 67. Lyon: IARC

International Collaboration on HIV and Cancer (2000) Highly active antiretroviral therapy and incidence of cancer in human immunodeficiency virus-infected adults. J Natl Cancer Inst 92: 1823-1830

Istituto Superiore di Sanità (ISS) (2001) Aggiornamento dei casi di AIDS notificati in Italia al 30 giugno 2001. Notiziario ISS 14(Suppl 1): 1-15. (www.iss.it/notiziario/Vol14N12/art5/htm)

Levi F, Franceschi S, Te V-C, Randimbison L, La Vecchia C (1995) Trends of skin cancer in the Canton of Vaud, 1976-92. Br J Cancer 72: $1047-$ 1053

Li Y, Law M, McDonald A, Correll P, Kaldor JM, Grulich A (2002) Estimation of risk of cancers before occurrence of acquired immunodeficiency syndrome in persons infected with human immunodeficiency virus. Am J Epidemiol 155: $153-158$

Mandelblatt JS, Kanetsky P, Eggert L, Gold K (1999) HIV infection a cofactor for cervical squamous cell neoplasia? Cancer Epidemiol Biomarkers Prev 8: $97-106$

Palefsky JM, Minkoff H, Kalish LA, Levine A, Sacks HS, Garcia P, Young M, Melnick S, Miotti P, Burk R (1999) Cervicovaginal human papillomavirus infection in human immunodeficiency virus-1 (HIV)-positive and highrisk HIV-negative women. J Natl Cancer Inst 91: 226-236

Parkin DM, Muir CS, Whelan SL, Gao YT, Ferlay J, Powell J (eds) (1992) Cancer Incidence in Five Continents, Vol. VI. IARC Sci Publ no. 120. Lyon: IARC

Parkin DM, Whelan SL, Ferlay J, Raymond L, Powell J (eds) (1997) Cancer Incidence in Five Continents, Vol. VII. IARC Sci Publ no. 143. Lyon: IARC

Parkin DM, Whelan SL, Ferlay J, Teppo L, Thomas DB (eds) (2002) Cancer Incidence in Five Continents, Vol. VIII. IARC Sci Publ. no. 155. Lyon: IARC

Pezzotti P, Serraino D, Rezza G, Dal Maso L, Vaccher E, Cozzi-Lepri A, Franceschi S (1999) The spectrum of AIDS-defining diseases: temporal rends in Italy prior to the use of highly active anti-retroviral therapies, 1982 - 1996. Int J Epidemiol 28: $975-981$

Serraino D, Boschini A, Carrieri P, Pradier C, Dorrucci M, Dal Maso L, Ballerini P, Pezzetti P, Smacchia C, Pesce A, Ippolito G, Franceschi S, Rezza G (2000) Cancer risk among men with, or at risk of, HIV infection in southern Europe. AIDS 14: 553-559

Serraino D, Carbone A, Franceschi S, Tirelli U, for the Italian Cooperative Group on AIDS and Tumours (1993) Increased frequency of lymphocyte 
depletion and mixed cellularity subtypes of Hodgkin's disease in HIVinfected patients. Eur J Cancer 29A: $1948-1950$

Serraino D, Pezzotti P, Dorrucci M, Alliegro MV, Sinicco A, Rezza G (1997) Cancer incidence in a cohort of human immunodeficiency virus seroconverters. Cancer 79: 1004-1008

Sitas F, Pacella-Norman R, Carrara H, Patel M, Ruff P, Sur R, Jentsch U, Hale M, Rowji P, Saffer D, Connoer M, Bull D, Newon R, Beral V (2000) The spectrum of HIV-1 related cancers in South Africa. Int J Cancer 88: 489-492

Smukler AJ, Ratner L (2002) Hepatitis viruses and hepatocellular carcinoma in HIV-infected patients. Curr Opin Oncol 14: 538-542

Sun X-W, Kuhn L, Ellerbrock TV, Chiasson MA, Bush TJ, Wright TC (1997) Human papillomavirus infection in women infected with the human immunodeficiency virus. $N$ Engl J Med 337: $1343-1349$

Tindle RW (2002) Immune evasion in human papillomavirus-associated cervical cancer. Nat Rev Cancer 2: 59-65

\section{APPENDIX}

Cancer and AIDS Registry Linkage Study: Diego Serraino (IRCCS 'L. Spallanzani', Rome); Gary Clifford (IARC Lyon, France); Eugenio Paci (Registro Tumori Toscano, Florence); Rosa Vattiato (Registro Tumori della Romagna, Forlì); Anna Rita Fiore (Registro Tumori del Veneto, Padova); Silvia Patriarca (Registro Tumori Piemonte, Torino); Claudia Casella (Registro Tumori Ligure, Genoa); Paolo Contiero, Giovanna Tagliabue (Registro Tumori Lombardia - Provincia di Varese); Maria Elisa Artioli, Katia Valla (Registro Tumori della Provincia di Modena); Vincenzo De Lisi, Lidia Serventi (Registro Tumori della Provincia di Parma); Francesco La Rosa, Fabrizio Stracci (Registro Tumori Umbro); Stefano Ferretti, Anna Rita Lombardi (Registro Tumori della Provincia di Ferrara); Massimiliano Oggiano, Amelia Sechi
Tirelli U, Spina M, Gaidano G, Vaccher E, Franceschi S, Carbone A (2000) Epidemiology, biological and clinical features of HIV-related lymphomas in the era of highly active antiretroviral therapy. AIDS 14: 1675-1688

Woodman CBJ, Collins S, Winter H, Bailey A, Ellis J, Prior P, Yates M, Rollason TP, Young LS (2001) Natural history of cervical human papillomavirus infection in young women: a longitudinal cohort study. Lancet 357: $1831-1836$

World Health Organization (1990) International Classification of Diseases for Oncology, 2nd edn. Genève: WHO

World Health Organization (1977) International Classification of Diseases, 9th Revision. Genève: WHO

World Health Organization (1992) International Classification of Diseases, 10th Revision. Genève: WHO

Zanetti R, Gafà L, Pannelli F, Conti E, Rosso S (eds) (2002) Cancer in Italy. Incidence Data from Cancer Registries, 3rd volume, 1993 - 1998. Roma: Il Pensiero Scientifico editore

(Registro Tumori della Provincia di Sassari); Silva Franchini, Maria Gentilini (Registro Tumori della Provincia di Trento); Ettore Conti, Valerio Ramazzotti (Registro Tumori di Popolazione della Provincia di Latina); Adriano Giacomin, Lucia Preto (Registro Tumori della Provincia di Biella); Gianni Vicario, Loris Zanier (Registro dei Tumori del Friuli-Venezia Giulia); Francesco Bellù, Fabio Vittadello (Registro Tumori dell'Alto Adige); Susanna Vitarelli, Franco Pannelli (Registro Tumori Provincia di Macerata, Camerino); Rosario Tumino, Lorenzo Gafà (Registro Tumori Ragusa); Maurizio Montella, Mario Fusco (Registro Tumori della Provincia di Napoli); Stefano Boros, Patrizio Pezzotti (Istituto Superiore di Sanità, Roma). 